\title{
The need to collect, aggregate, and analyze global anesthesia and surgery data
}

\section{La nécessité de collecter, regrouper et analyser les données sur l'anesthésie et la chirurgie dans le monde}

\author{
Sabrina Juran, PhD • Magdalena Gruendl, MPH $\cdot$ Isobel H. Marks, MD • \\ P. Niclas Broer, MD • Jose Miguel Guzman, PhD • Justine Davies, MBChB, MD • \\ Mark Shrime, MD, MPH, PhD, FACS • Walter Johnson, MD, MBA, MPH • \\ Hampus Holmer, MD • Gregory Peck, DO, FACS · Emmanuel Makasa, MD • \\ Lars Hagander, MD, PhD, MPH • Stephanie J. Klug, MPH, PhD • \\ John G. Meara, MD, DMD, MBA · Adrian W. Gelb, MBChB, FRCPC $\cdot$ David Ljungman, MD, PhD
}

Received: 5 July 2018/Revised: 16 August 2018/Accepted: 17 August 2018/Published online: 27 November 2018

(C) Canadian Anesthesiologists' Society 2018

\begin{abstract}
In the Sustainable Development Goals era, there is a new awareness of the need for an integrated approach to healthcare interventions and a strong commitment to Universal Health Coverage. To achieve the goal of strengthening entire health systems, surgery, as a crosscutting treatment modality, is indispensable. For any health system strengthening exercise, baseline data and longitudinal monitoring of progress are necessary. With improved data capabilities, there are unparalleled possibilities to map out and understand systems,
\end{abstract}

This article is accompanied by an editorial. Please see Can J Anesth 2018; 65: this issue.

S. Juran, PhD (ه)

Department of Epidemiology, Technical University Munich,

Munich, Germany

e-mail: sabrinajuran@gmail.com

Technical Division, United Nations Population Fund, New York, NY, USA

\section{Gruendl, MPH}

Department of Epidemiology, Technical University Munich, Munich, Germany

Program in Global Surgery, Department of Global Health and Social Medicine, Harvard Medical School, Boston, MA, USA

I. H. Marks, MD

Northwick Park Hospital, Imperial College London, London, UK

P. N. Broer, MD

Klinikum Bogenhausen, Technical University Munich, Munich, Germany integrating data from many sources and sectors. Nevertheless, there is also a need to prioritize among indicators to avoid information overload and data collection fatigue. There is a similar need to define indicators and collection methodology to create standardized and comparable data. Finally, there is a need to establish data pathways to ensure clear responsibilities amongst national and international institutions and integrate surgical metrics into existing mechanisms for sustainable data collection. This is a call to collect, aggregate, and analyze global anesthesia and surgery data, with an account of existing data sources and a proposed way forward.

\section{J. M. Guzman, PhD}

The Demographic and Health Survey Program, ICF, Fairfax, VA, USA

J. Davies, MBChB, MD

School of Population Sciences and Health Services Research Faculty of Life Sciences and Medicine, King's College London, London, UK

M. Shrime, MD, MPH, PhD, FACS

Program in Global Surgery, Department of Global Health and Social Medicine, Harvard Medical School, Boston, MA, USA

Department of Otolaryngology, Massachusetts Eye and Ear Infirmary, Boston, MA, USA

W. Johnson, MD, MBA, MPH

World Health Organization, Geneva, Switzerland 
Résumé À l'époque des objectifs du développement durable, on constate une nouvelle sensibilisation au besoin d'une approche intégrée dans les interventions en soins de santé et un fort engagement en faveur d'une couverture médicale universelle. Pour atteindre l'objectif du renforcement de systèmes entiers de santé, la chirurgie en tant que modalité thérapeutique transversale est indispensable. Pour toute activité de renforcement du système de santé, des données de référence et un suivi longitudinal des progrès sont nécessaires. Avec de meilleures données, il existe des possibilités sans équivalent de cartographier et de comprendre les systèmes, en intégrant des données provenant de multiples sources et secteurs. Néanmoins, il est également nécessaire de prioriser les indicateurs pour éviter une surcharge d'informations et une fatigue dans la collecte des données. Il existe un besoin similaire de définition des indicateurs et de la méthodologie de collecte afin de créer des données standardisées et comparables. Enfin, il est nécessaire d'établir des cheminements de données pour garantir des responsabilités claires entre les institutions nationales et internationales et intégrer les paramètres chirurgicaux dans les mécanismes existants pour une collecte durable des données. Ceci est un appel à la collecte, au regroupement et à l'analyse de données globales en anesthésie et en chirurgie avec un compte rendu des sources de données existantes et une proposition d'avancée.

There is increasing acknowledgement of the linkage between universal access to surgical, obstetric, anesthesia, and trauma care and global sustainable

H. Holmer, MD - L. Hagander, MD, PhD, MPH

Lund University, WHO Collaborating Centre for Surgery and

Public Health, Lund, Sweden

G. Peck, DO, FACS

Rutgers Global Surgery, Rutgers Biomedical Health Sciences, Newark, NJ, USA

E. Makasa, MD

Department of Surgery, School of Clinical Medicine, Faculty of Health Sciences, University of Witwatersrand, Johannesburg, South Africa

\section{S. J. Klug, MPH, PhD}

Department of Epidemiology, Technical University Munich, Munich, Germany

J. G. Meara, MD, DMD, MBA

Program in Global Surgery, Department of Global Health and Social Medicine, Harvard Medical School, Boston, MA, USA development. The international 2030 sustainable development agenda with its aspiration to Universal Health Coverage (UHC), and the 2015 World Health Assembly (WHA) Resolution $68.15^{1}$ together with Decision WHA70 ${ }^{2}$ recognize the importance of UHC for surgical care and anesthesia. As such, there has never been a more opportune time for members of the international community to support the integration of surgical and anesthesia care into the global health agenda.

In the report Global Surgery 2030: Evidence and Solutions for Achieving Health, Welfare, and Economic Development, ${ }^{2}$ it is estimated that five billion people do not have access to safe, affordable surgical and anesthesia care when needed and that one third of the global burden of disease requires surgical care or anesthesia-pain management, or both. Surgical disease encompasses any illness where outcomes can be improved through surgical care. ${ }^{3,4}$ Access is most limited in low- and middle-income countries (LMICs) where nine out of ten people cannot access basic surgical care. Untreated, many surgical conditions are a source of lifetime disability and can cause premature mortality. ${ }^{5}$ Surgical conditions claim an estimated 16.9 million lives per year. ${ }^{3}$

In 2012, it was estimated that 143 million additional surgical procedures are needed in LMICs every year to prevent disability and economic loss and to save lives. Of the 313 million procedures undertaken each year worldwide, only $6 \%$ occur in the poorest countries where over one third of the world's population lives. ${ }^{6}$ Low operative case volumes are associated with higher complication rates and higher case-fatality rates from common, treatable surgical conditions. The unmet need is greatest in eastern, western, and central sub-Saharan Africa and south Asia. ${ }^{2}$

In 2015, the World Bank launched the first volume of its Disease Control Priorities $3{ }^{\text {rd }}$ Edition, dedicated to "essential

Department of Plastic \& Oral Surgery, Boston Children's

Hospital, Harvard Medical School, Boston, MA, USA

A. W. Gelb, MBChB, FRCPC

Department of Anaesthesia \& Perioperative Care, University of California San Francisco, San Francisco, CA, USA

D. Ljungman, $\mathrm{MD}, \mathrm{PhD}$

Program in Global Surgery, Department of Global Health and Social Medicine, Harvard Medical School, Boston, MA, USA

Department of Surgery, Institute of Clinical Sciences, Sahlgrenska Academy, University of Gothenburg, Gothenburg, Sweden 
surgery", where 44 surgical procedures were identified as essential for population health. ${ }^{7}$ The range of diseases requiring surgical capacity is wide and includes the growing burden of non-communicable diseases such as diabetes, cardiovascular disease, and cancer as well as injuries sustained from road traffic accidents, natural disasters, humanitarian crises, and conflicts. Further, it is estimated that 33 million individuals face catastrophic health expenditure, defined as an expense $>10 \%$ of a household's yearly expenditure, due to out-of-pocket payments for surgery and anesthesia care each year. ${ }^{8}$ An additional 48 million cases of catastrophic expenditure are attributable to the non-medical costs of accessing surgical care such as transportation. ${ }^{8}$ Globally, a quarter of people who have a surgical procedure incur financial catastrophe as a result of seeking care. Investing in surgical services in LMICs is affordable, saves lives, and promotes economic growth. The cost to scale up surgical systems to meet the minimum requirements in LMICs as suggested by the LCoGS is estimated at US\$ 350 billion. ${ }^{9}$ This is a small investment compared with the estimated US\$ 12.3 trillion loss of production in these countries if this is not undertaken. ${ }^{10}$ It is also important to see that the major shifts in global population dynamics through population age structure, particularly aging, very rapid urban population growth, high mortality due to non-intentional injury and violence, and increased migration will increase the need for working surgical systems in the future. Demographic and epidemiologic transitions are reshaping the requirements for investments in health.
The demographic structure, pace of growth, and relative size of a population impact the current and future demand for surgical care. The world population continues to grow, although at a slower pace than in recent decades. Between 2015 and 2050, an estimated 2.4 billion people are projected to enter the world population. Africa is the region with the highest rate of population growth, currently growing at $2.55 \%$ annually. ${ }^{11}$ The implications of population growth are particularly relevant as more than half of global population growth until 2040 is projected to occur in Africa. These structural changes are reshaping the requirements for investing in health and changing related policy measures. Population growth accentuates the current deficit in access to surgical care. Significant actions to strengthen health systems are warranted to achieve universal access to surgical and anesthesia care.

Surgery and anesthesia are an "indivisible, indispensable part of health care". ${ }^{12}$ Indeed, surgical and anesthesia services are inherent to (and span across) diverse disciplines, such as oncology, injury, cardiovascular disease, infections, pain management, and reproductive, maternal, neonatal, and child healthcare. Surgical and anesthesia care is a prerequisite for all people to live to their fullest potential and for the attainment of local and global health targets.

Universal Health Coverage and the health aspirations set out in the 2030 agenda and its 17 sustainable development goals (SDGs) will be impossible to achieve without ensuring that safe, timely, and affordable surgical,

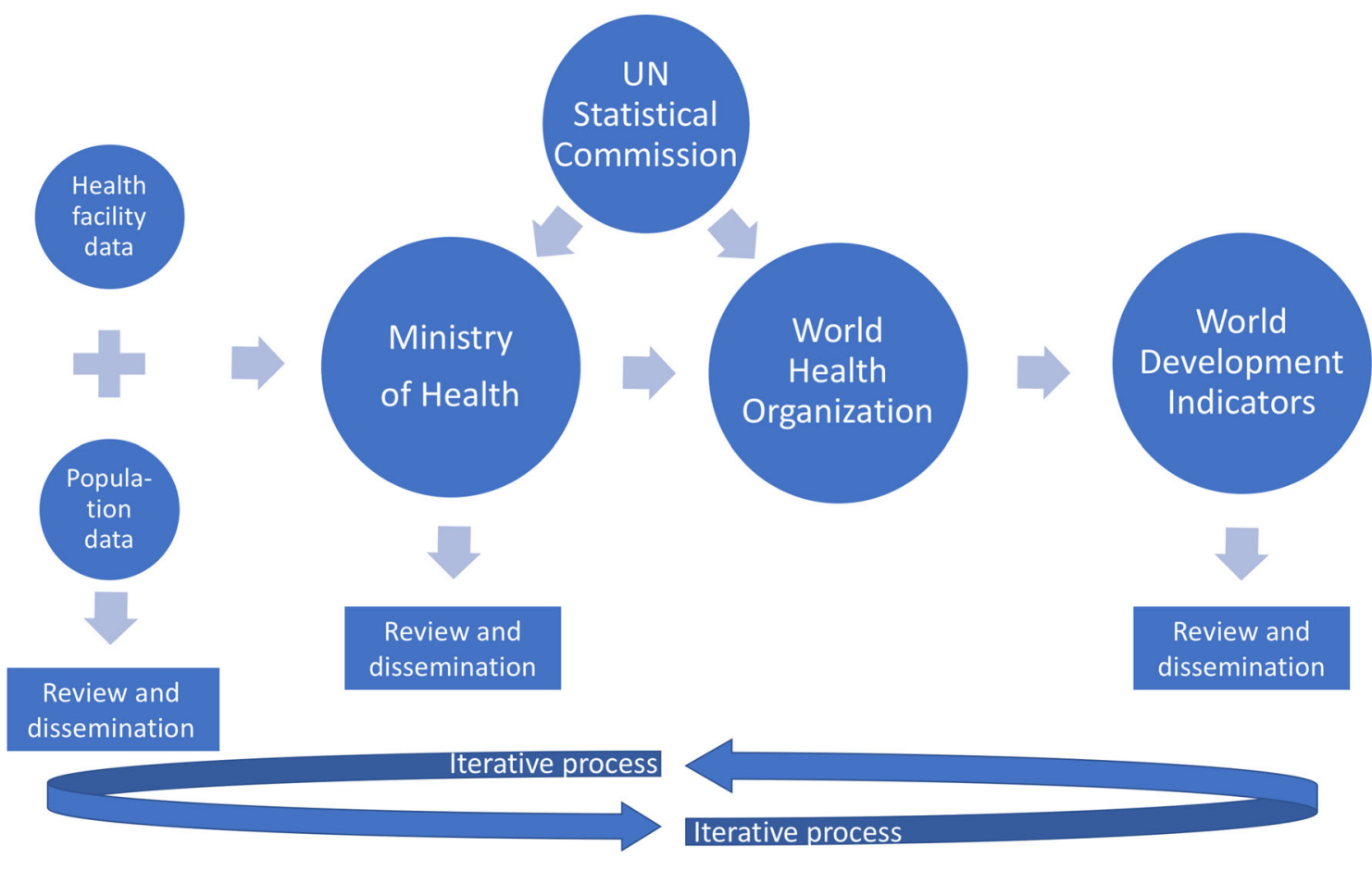

Fig. 1 Proposed mechanism of data collection and utilization 
obstetric, and anesthesia care is available and accessible. Within the changing global health landscape, surgical, obstetric, and anesthesia care should therefore form an integral component of national health systems in all countries, and the commitment to do so has already been made through the unanimous passing of the World Health Organization (WHO) resolution WHA 68.15. Baseline data and longitudinal monitoring of progress are a necessary component of health system strengthening. This can be achieved by creating standardized and comparable data sources. Surgical and anesthesia services require an adequate needs assessment such that policymakers can better understand present and projected demands. Indeed, baseline measurement is the first step toward understanding benchmarks.

This article will guide the reader through different data sources and potential improvements in data collection mechanisms to report on and monitor progress toward access to surgery and anesthesia care (Fig. 1).

\section{Measurement in global surgery}

While a wealth of global health data has been accrued, there is still a major gap in knowledge with respect to surgical inequities. This poses a challenge for policymakers in attempting to improve such services-i.e., they cannot change what is unmeasured. Therefore, at the global level, improvements in data collection are necessary to monitor progress towards UHC and the health-related SDGs. Highquality, timely, and reliable surgery and anesthesia data that are available, accessible, and can be applied (especially in resource poor areas) need significant coordination. Recognizing the paucity of global data collection in this area and the process to improve it, the 2015 WHO resolution WHA68.15 urged Member States to collect and compile data on the number, type, and indications of surgical procedures, referrals, and perioperative mortality in their respective countries and to share such data as appropriate. ${ }^{1}$ In 2017 , the WHO Decision Point WHA70.22 further requested that the WHO Director-General biennially report to the World Health Assembly on the progress towards strengthening of emergency and essential surgical care and anesthesia as outlined in resolution 68.15 as part of the WHO and its Member States' work under UHC and the 2030 agenda for sustainable development. ${ }^{13}$

\section{Current global anesthesia and surgery metrics}

Global surgery and anesthesia statistics depend on definitions of statistical units and populations for comparison and linkage. Surgical target goals are based on ensuring that a certain percentage of the population has access to specific services or resources or achieves a certain level of social, economic, or physical health. These measurements require a solid and regularly updated understanding of not only the number of people that live in a specific geo-location or country, but also other demographic descriptors (Fig. 2). ${ }^{14}$ Variables and classification systems are crucial to properly define, and then uniformly apply, consensus definitions in all nations. Various data sources and processes that are necessary,
Fig. 2 Definitions of global surgery, global surgery data, and the Bellwether procedures

Global surgery encompasses anaesthesia, all surgical specialties including trauma surgery,
general surgery, obstetrics \& gynaecology, perioperative medicine, critical emergency medicine,
pain management and palliative care, rehabilitation, nursing and other health professions
involved in the care of the surgical patient. Global Surgery is defined as "an area of study,
research, practice, and advocacy that seeks to improve health outcomes and achieve health equity
for all people who require surgical care, with a special emphasis on underserved populations and
populations in crisis. It uses collaborative, cross-sectoral, and transnational approaches and is a
synthesis of population-based strategies with individual surgical care." [13]
Global Surgery Data refer to data that are composed of a universally collected minimal set of
indicators for surgical systems evaluation. The collection is intended to be layered; in essence
that once the first set is collected further sets of indicators could be added for greater granularity
and richer data. The data is presented disaggregated for facilities for internal quality
improvement, for regions and nations for allocation decisions and aggregated for the global
community for benchmarking and best practice discussions.
The Bellwether Procedures - caesarean delivery, laparotomy and open fracture treatment -
serve as proxy indicators for surgical facilities that have the ability to provide a broad range of
procedures.' [14] These procedures are proxies, signalling a level of care that district hospitals
worldwide should be able to provide. Therefore, hospitals do not need to provide exactly these
three but should aim to be capable of doing cases of similar calibre.


Table 1 Core indicators to monitor realization of universal access to safe, affordable surgical and anesthesia care when needed ${ }^{22}$

\begin{tabular}{|c|c|c|c|c|}
\hline Indicator & Definition & Data Source & $\begin{array}{l}\text { Responsible } \\
\text { Entity }\end{array}$ & Target \\
\hline \multicolumn{5}{|c|}{ Group 1: Preparedness for surgical and anesthesia care } \\
\hline $\begin{array}{l}\text { Access to timely } \\
\text { essential } \\
\text { surgery }\end{array}$ & $\begin{array}{l}\text { Proportion of the population that can } \\
\text { access, within } 2 \text { hours a facility that can } \\
\text { do Cesarean delivery, laparotomy, and } \\
\text { treatment of open fracture (the } \\
\text { Bellwether procedure) }\end{array}$ & $\begin{array}{l}\text { Facility records and } \\
\text { population } \\
\text { demographics }\end{array}$ & $\begin{array}{l}\text { Ministry of } \\
\text { Health }\end{array}$ & $\begin{array}{l}\text { A minimum of } 80 \% \text { coverage of essential } \\
\text { surgical and anesthesia services per } \\
\text { country by } 2030\end{array}$ \\
\hline $\begin{array}{l}\text { Specialist } \\
\text { surgical } \\
\text { workforce } \\
\text { density }\end{array}$ & $\begin{array}{l}\text { Number of specialist surgical, anesthetic, } \\
\text { and obstetric physicians who are working } \\
\text { per } 100,000 \text { population }\end{array}$ & $\begin{array}{l}\text { Facility records } \\
\text { data from } \\
\text { training and } \\
\text { licensing bodies }\end{array}$ & $\begin{array}{l}\text { Ministry of } \\
\text { Health }\end{array}$ & $\begin{array}{l}100 \% \text { of countries with at least } 20 \text { surgical, } \\
\text { anesthetic and obstetric physicians per } \\
100,000 \text { population by } 2030\end{array}$ \\
\hline \multicolumn{5}{|c|}{ Group 2: Delivery of surgical and anesthesia care } \\
\hline Surgical volume & $\begin{array}{l}\text { Procedures done in an operating theater, per } \\
100,000 \text { population per year }\end{array}$ & Facility records & $\begin{array}{l}\text { Facility, } \\
\text { Ministry } \\
\text { of Health }\end{array}$ & $\begin{array}{l}80 \% \text { of countries by } 2020 \text { and } 100 \% \text { of } \\
\text { countries by } 2030 \text { tracking surgical } \\
\text { volume; } 5,000 \text { procedures per } 100,000 \\
\text { population by } 2030\end{array}$ \\
\hline $\begin{array}{l}\text { Perioperative } \\
\text { mortality }\end{array}$ & $\begin{array}{l}\text { All-cause death rate before discharge in } \\
\text { patients who have had a procedure in an } \\
\text { operating theater, divided by the total } \\
\text { number of procedures, presented as } \\
\text { percentage }\end{array}$ & $\begin{array}{l}\text { Facility records and } \\
\text { death registries }\end{array}$ & $\begin{array}{l}\text { Facility, } \\
\text { Ministry } \\
\text { of Health }\end{array}$ & $\begin{array}{l}80 \% \text { of countries by } 2020 \text { and } 100 \% \text { of } \\
\text { countries by } 2030 \text { tracking perioperative } \\
\text { mortality; in } 2020 \text {, assess global data and } \\
\text { set national targets for } 2030\end{array}$ \\
\hline \multicolumn{5}{|c|}{ Group 3: Effect of surgical and anesthesia care } \\
\hline $\begin{array}{l}\text { Protection } \\
\text { against } \\
\text { impoverishing } \\
\text { expenditure }\end{array}$ & $\begin{array}{l}\text { Proportion of households protected against } \\
\text { impoverishment from direct out-of- } \\
\text { pocket payments for surgical and } \\
\text { anesthesia care }\end{array}$ & $\begin{array}{l}\text { Household surveys, } \\
\text { facility records }\end{array}$ & $\begin{array}{l}\text { World Bank, } \\
\text { WHO, } \\
\text { USAID }\end{array}$ & $\begin{array}{l}100 \% \text { protection against impoverishment } \\
\text { from out-of-pocket payments for surgical } \\
\text { and anesthesia care by } 2030\end{array}$ \\
\hline $\begin{array}{l}\text { Protection } \\
\text { against } \\
\text { catastrophic } \\
\text { expenditure }\end{array}$ & $\begin{array}{l}\text { Fraction of households protected against } \\
\text { catastrophic expenditure from direct out- } \\
\text { of-pocket payments for surgical and } \\
\text { anesthesia care }\end{array}$ & $\begin{array}{l}\text { Household surveys, } \\
\text { facility records }\end{array}$ & $\begin{array}{l}\text { World Bank, } \\
\text { WHO, } \\
\text { USAID }\end{array}$ & $\begin{array}{l}100 \% \text { protection against catastrophic } \\
\text { expenditure from out-of-pocket } \\
\text { payments for surgical and anesthesia care } \\
\text { by } 2030\end{array}$ \\
\hline
\end{tabular}

USAID = United States Agency for International Development; WHO = World Health Organization

however, should at a minimum include population and housing censuses, a sample community, hospital surveys, and health information systems. To comprehensively, but not resource intensively, assess a surgical care system with a limited set of measures, the LCoGS identified as a priority the collection of a standardized set of six core surgical indicator data. ${ }^{2}$ These six indicators assess the preparedness, delivery, and impact of surgical care and are outlined in Table 1.

The indicators were reflected in the WHO 100 core health indicators ${ }^{15}$ (Table 2) and subsequently also accepted for inclusion in the World Bank's world development indicators data set, $^{16}$ where data are currently available for four of the indicators (Table 3).

In the most recent SDG atlas by the World Bank, ${ }^{17}$ the surgical workforce indicator is featured with a graphic visualization. While even some high-income countries are lacking enough health workers to meet the demand of the local population, low-income countries have ten times fewer physicians than high-income countries do. ${ }^{18}$
Shortages are severe in terms of surgical, anesthesia, and obstetric (SAO) care.

\section{Evaluation of the present situation and need for action}

Following the publication of the LCoGS report in July 2015, Commission members at the Program for Global Surgery and Social Change based at Harvard Medical School began to collect nationally representative data for each indicator in the 215 countries and independent economies recognized by the World Bank. ${ }^{19}$ This was the first attempt to systematically and comprehensively gather primary data on surgical systems to improve previously fragmented estimates. In 2017, a second round of data collection was carried out under the leadership of the International Student Surgical Network and King's College London. $^{20}$ Anesthesia-related data in Africa, Central America, and India are currently being collected by the World Federation of Societies of Anaesthesiologists 
Table 2 Surgical indicators in the WHO 100 Core Health Indicators $(2018)^{16}$

\begin{tabular}{l} 
Indicator \\
\hline Health worker density and distribution \\
Health facility density and distribution \\
(also: access to emergency surgery) \\
Completeness of reporting by facilities \\
(also: completeness and timeliness for \\
notifiable diseases) \\
Outpatient service utilization (also: \\
inpatient admissions and surgical \\
volume) \\
Service-specific availability and readiness
\end{tabular}

Perioperative mortality rate

Coverage of essential health services

Proportion of the population with impoverishing health expenditure

Proportion of the population with large household expenditure on health as a share of total household consumption or income
Definition

Number of health workers per 1,000 population, disaggregated by number of surgeons, anesthetists, and obstetricians by place of employment (rural/urban and district)

Disaggregated by emergency surgery; percentage of the population that can access, within 2 hours, a facility that can perform Bellwether procedures - emergency Cesarean delivery, laparotomy, and open fracture fixation

Percentage of facilities that submit reports within the required deadline

Number of outpatient department visits per person per year

Number of health facilities offering specific services per 10,000 population and meeting minimum service standards on the basis of a set of tracer criteria for specific services, etc.

All-cause death rate prior to discharge among patients having one or more procedures in an operating theatre during the relevant admission

Universal health coverage (UHC) includes both access to quality health services and medicines and financial risk protection. The coverage of essential health services, as defined by SDG indicator 3.8.1, is the average coverage of essential services based on tracer interventions that include reproductive, maternal, newborn and child health, infectious diseases, non-communicable diseases, and service capacity and access among the general and the most disadvantaged population. These tracer indicators are combined into a service coverage index, which provides a summary indicator of service coverage

Proportion of the population where a household's total consumption expenditure or income including household expenditure on health is greater than the poverty line but the household's total consumption expenditure or income excluding household expenditure on health is below the poverty line

Proportion of the population the population with large household expenditure on health as a share of total household expenditure or income

$\mathrm{SDG}=$ sustainable development goals

(WFSA) and University of California San Francisco Anesthesia Global Health in Africa, Central America, and India.

The first report of the LCoGS on the six surgical indicators was created with data received from 64 countries in November 2015. ${ }^{21}$ The volume of data was sufficient for primary data for indicator 2 and modeled data for indicators 3, 5, and 6 to be included in the 2016 World Bank Development Indicators. A mixed methods approach to collecting these data included data retrieval through 1) direct contact with official bodies, 2) systematic reviews of published literature, and 3) internet searches of the grey literature. ${ }^{22}$ The second round of data collection has yielded similar amounts of data (manuscript in preparation). Hence, the number of countries providing data for at least one time point in the last years along the six indicators varies significantly.
These two rounds of data collection have been driven by academic institutions in high-income countries and we argue that this is an unsustainable model going forward. National data collection processes need to be owned and driven at the local level by the respective National Statistical Offices and Ministries of Health as they are the key stakeholders in the collection and utilization of health statistics. National realities and priorities must guide data collection to achieve national ownership and sustainability. Additionally, data collection across multiple countries must be harmonized and standardized to ensure comparability of data and benchmarking of achievements. The structure would ideally be that Ministries of Health report data to WHO that then sends this on to be freely and transparently available at the World Development Indicators platform of the World Bank. Another data dissemination platform is the WHO Global Health Observatory. 
Table 3 Indicators with data in the World Development Indicators ${ }^{17}$

\begin{tabular}{|c|c|}
\hline Indicator & Definition \\
\hline $\begin{array}{l}\text { Specialist surgical workforce (per } 100,000 \\
\text { population) }\end{array}$ & $\begin{array}{l}\text { Specialist surgical workforce is the number of specialist surgical, anesthetic, and obstetric } \\
\text { providers who are working in each country per } 100,000 \text { population }\end{array}$ \\
\hline $\begin{array}{l}\text { Number of surgical procedures (per } 100,000 \\
\text { population) }\end{array}$ & $\begin{array}{l}\text { The number of procedures undertaken in an operating theatre per } 100,000 \text { population per year } \\
\text { in each country. A procedure is defined as the incision, excision, or manipulation of tissue } \\
\text { that needs regional or general anesthesia or profound sedation to control pain. }\end{array}$ \\
\hline $\begin{array}{l}\text { Risk of impoverishing expenditure for surgical } \\
\text { care ( } \% \text { of people at risk) }\end{array}$ & $\begin{array}{l}\text { The proportion of population at risk of impoverishing expenditure when surgical care is } \\
\text { required. Impoverishing expenditure is defined as direct out-of-pocket payments for surgical } \\
\text { and anesthesia care that drive people below a poverty threshold (using a threshold of } \$ 1.25 \\
\text { PPP/day) }\end{array}$ \\
\hline $\begin{array}{l}\text { Risk of catastrophic expenditure for surgical } \\
\text { care ( } \% \text { of people at risk) }\end{array}$ & $\begin{array}{l}\text { The proportion of population at risk of catastrophic expenditure when surgical care is required. } \\
\text { Catastrophic expenditure is defined as direct out of pocket payments for surgical and } \\
\text { anesthesia care exceeding } 10 \% \text { of total income }\end{array}$ \\
\hline
\end{tabular}

\section{Data sources for surgical statistics}

Despite surgical and anesthesia data still being limited in availability, the WHO service availability and readiness assessments (SARA) and the WHO-SAT administered by the WHO global initiative on emergency and essential surgical care have collected substantial data at the facility level. Other organizations have also contributed to the systematic collection of data relating to surgical care. ${ }^{23-26}$ Effective sampling methods represent an option to lessen the statistical burden placed on the national statistical system while capturing representative data at the subnational level. ${ }^{27}$

A current research collaboration between the German Global Surgery Association and WorldPop/Flowminder Foundation is exploring possible data capture techniques to accurately represent national data, respecting national statistical laws, while considering national budget and human resource constraints. From previous data collection initiatives, it has become apparent that certain components are needed for standardized and sustainable high-quality data collection (Table 4).

Data from different sources are used for multiple purposes at different levels of the healthcare system: health information systems, hospital records, population and housing censuses, sample and household surveys, facility-based surveys, vital statistics systems, and population registers. These are all key examples of existing data collection mechanisms important for global surgery data collection. Each is presented in more detail below (Fig. 3). Given the interrelationship between surgery and the wider health and social development of nations, other indicators, including demographic, socio-economic, and financial indicators, are important to better understand surgical care and the needs of populations within these contexts. Examples include population distribution by age, sex, geography, population density, geospatial information on health facilities, gross domestic product per capita, infrastructure development, electricity, water supply, health expenditure, and out-of-pocket cost of surgery insurance systems.

Data sources for surgery statistics can be divided into two categories: 1) facility-based data such as hospital and facility records and individual patient records and 2) population-based approaches, including population and housing censuses, civil registration and vital statistics, and population sample surveys.

Data collection approaches may fit both categories of sources and provide important information that may not be available elsewhere-i.e., research and information by community-based organizations and professional medical associations. Patient-level data, including information on the patient demographics, diagnosis, and treatment, serve as the basis for clinical decision-making. Population-level data are essential for public health decision-making and can generate information not only about those who use health services but also about those who do not use them and why. Health facility-level data, from both aggregated facility-level data and administrative data sources, enable healthcare managers to determine resource needs; guide purchasing decisions for medications, equipment, and supplies; and develop community outreach. Such data can provide immediate and ongoing information relevant to public health decision-making, especially if data are of high quality, representative of the services available to the population as a whole, and related to all facilities (i.e., public, non-state actor or privately driven). ${ }^{28}$ Health information systems (HIS) refer to any system that captures, stores, manages, or transmits information related to the health of individuals or the activities of organizations that work within the health sector. These HIS are essential for monitoring and evaluation, providing an 
Table 4 Summary recommendations

Form a working group of international experts led by the WHO EESC program to prioritize among existing and potential indicators and find consensus on definitions, reporting, and dissemination

Arrange for an international conference dedicated to surgery and anesthesia statistics

Draft a report that highlights the challenges associated with the collection, compilation, and dissemination of statistics on global anesthesia and surgery statistics, including the lack of consistent terminology, need for additional data sources, and difficulties in comparing international statistics

Draft an action plan for the development, collection, analysis, and dissemination of global anesthesia-surgery statistics

Submit draft report and action plan to the United Nations Statistical Commission in 2020

Upon acceptance of the work plan by the United Nations Statistical Commission, create a collector's manual for standardized reporting by Member States

Implement annual integrated data collection by facilities and at the population level to inform decision makers at each administrative level. The data should be aggregated and reported by Member States to WHO and dissemination via the World Bank World Development Indicators and World Health Organization Global Health Observatory platforms

EESC $=$ emergency and essential surgical care; $\mathrm{WHO}=$ World Health Organization

Fig. 3 Key components of high-quality data collection
- Consistency of terminology, definitions and data collection methodology

- Data collection integrated into health system and existing surveys

- Avoiding additional burden of non-standardized data collection

- Guidance on systematic operationalization and data collection mechanisms

- Improved application of data at sub-national, national and global levels to improve services

- Standardization for internationally comparable statistics alert and early warning capability, supporting patient and health facility management, enabling planning, supporting and stimulating research, permitting health situation and trends analysis, supporting global reporting, and underpinning communication of health challenges to diverse users. A good HIS brings together all relevant partners to ensure that users have access to reliable, official, useable, understandable, and comparable data. ${ }^{28}$

\section{Facility records}

Facility records include a variety of types of medical notes entered by healthcare professionals over time, recording observations and administration of medication and therapies, laboratory test results, radiology and other medical reports, orders for the administration of drugs and therapies, and other miscellaneous records. Facility records are traditionally compiled and maintained by healthcare providers in the hospital and clinics. Yet, advances in internet or web-based data storage have led to the development of personal health records, sometimes maintained by patients themselves. Facility-based patient exit surveys are an excellent source for collecting information on the true out-of-pocket cost for surgical procedures (i.e., indicators 5 and 6 ).

Electronic medical records provide the opportunity for healthcare organizations and institutions to improve the quality of patient care and safety and also have the potential to reduce costs and improve efficiency of the workplace. ${ }^{29}$ The use of electronic records has distinct advantages over paper records, including enabled access to medical records from remote locations and improved speed and ease of retrieval of records, research, and avenues to flag abnormal results. ${ }^{30}$

\section{Population and housing censuses}

The most comprehensive source of population data in most countries is the population census. Censuses generally provide population numbers, household or family size and composition, and information on sex and age distribution. They often include other demographic, economic, and health-related topics as well. The unique advantage of the census is that it represents the entire statistical universe, down to the smallest geographical unit, of a country or region. Further, the census is usually the starting point for household surveys. Nevertheless, it is not common practice in a census to ask questions related to surgery. Globally, as of right now, surgery is not classified as a core topic in international census recommendations, and there is no recommendation on the inclusion of a question on need for surgery in population censuses. ${ }^{31}$ 


\section{Population registers}

Population registers can be described as a mechanism of continuous recording of selected information pertaining to each member of the resident population of a country to provide up-to-date information concerning the size and characteristics of that population. Population registers have become an important source of information for various statistical surveys, including the population census. Basic characteristics that may be included in a population register are date and place of birth, sex, date and place of death, date of arrival/departure, citizenship(s), and marital status, which are important indicators for baseline assessments regarding surgery globally. ${ }^{31}$

\section{Household surveys}

Several standardized international sample surveys have been designed for special purposes. Household surveys, such as the Demographic and Health Survey (DHS), ${ }^{32}$ Multiple Indicator Cluster Survey, ${ }^{33}$ and Integrated Household Survey, have become a primary source of data in developing countries. Yet, household surveys are important everywhere as they are the most reliable data source to measure indicators related to health, nutrition, and other health factors on children, women, and men. ${ }^{28}$ Compared with population censuses (and administrative registers), sample surveys can go into far greater depth and ask many more questions.

Household surveys, in fact, could provide a useful source of detailed information on the characteristics and situations of populations in need of surgical treatment. In some surveys, verbal autopsy has been used to gather health information about a deceased individual to determine cause of death (i.e., cases related to maternal deaths). The advantage of these existing surveys is that they both cover a wide range of countries and are conducted in a regular, standardized, and systematic manner. It is absolutely feasible and desirable to integrate specifically designed question modules that represent anesthesia-surgical indicator categories (i.e., preparedness, delivery, and outcomes such as financial risk protection) into these surveys to study population-level surgery and anesthesia demand and supply. A pilot on surgical questions is currently underway in the DHS survey in Zambia this year.

\section{Health facility assessments}

The WHO emergency and essential surgical care program's situational analysis tool (WHO-SAT) was developed to evaluate the readiness of facilities to provide surgical care. ${ }^{34}$ This tool has been implemented in numerous settings worldwide over the past ten years and has subsequently been revised by the Harvard Medical School Program in Global Surgery and Social Change. ${ }^{34,35}$

Data pertinent to a country's health service delivery, including surgical delivery, are also collected in the Service Provision Assessment (SPA) survey developed by ICF International (Fairfax, VA, USA) under the United States Agency for International Development-funded DHS program. The key services and topics assessed in a SPA survey are: infrastructure, resources, systems, child health, maternal and newborn health, family planning, human immunodeficiency virus/acquired immunodeficiency syndrome, sexually transmitted infections, malaria, tuberculosis, basic surgery, and non-communicable diseases. $^{36}$

Subsequently drawing on experiences from the SPA, the WHO has developed another comprehensive tool, the SARA. ${ }^{37}$ This survey includes ample data relevant to surgery. Service availability is assessed by the collection of indicators in the three categories of health infrastructure, health workforce, and health utilization. Service readiness is assessed from tracer indicators in the five domains: 1) staff and guidelines, 2) diagnostics, 3) medicines and commodities, and 5) equipment and diagnostics. The Emergency and Essential Surgical Care program at WHO is currently involved in the process of compiling a new Health Facility Assessment tool using key items from SARA, SPA, and many of the current disease-specific tools. The WFSA have developed an anesthesia facility assessment tool, some of which will be integrated into SARA but will also be available as a stand-alone (www. wfsahq.org/afat).

\section{Vital statistics systems}

Components of a vital statistics systems refer to legal registration and statistical reporting as well as the collection, compilation, and dissemination of statistics pertaining to vital events (including events concerning life and death of individuals as well as their family and civil status). The vital events of interest to surgery and anesthesia are: live births, deaths, and maternal and fetal deaths. ${ }^{31}$ The quality of demographic and epidemiologic data depends on the extent to which countries have a functioning system of vital statistics. Monitoring the status of vital statistics is the first step to guiding and assisting those in need. Vital statistics are not always available for all countries in the world. Many LMICs have only rudimentary systems, which cannot fulfill statistical or legal purposes. For some, basic birth and death statistics 
can only be obtained from other tools, such as sample surveys and projection models. This may be a place to focus education and training as well as workforce expansion.

\section{Recommendations}

This report has highlighted the challenges faced when assessing surgical disease patterns. It has also addressed issues of access, quality, and financing of surgical and anesthesia services and related systems worldwide.

There is much to be gained from improved international coordination on global surgery and anesthesia data collection that would enable high-quality standards for obtaining official statistics. Limited global, regional, or country-specific coordination results in incoherent support, major funding gaps, or duplicative funding of specific tasks, indirectly encouraging countries to postpone critical decisions and progress.

Another consequence is the over scheduling of scarce host-country resources to service multiple data collection efforts, resulting in poorly sequenced activities, lost institutionalization opportunities, and collection of data of compromised quality. These issues have become more severe with the increasing scarcity of financial resources in support of statistical activities worldwide and nonstandardized external global surgery collaborative efforts. Cooperation among National Statistical Offices, Ministries of Health, health facilities, providers, professional societies, non-governmental organizations, academia, and international organizations is necessary to ensure comprehensive and appropriate data collection and utilization.

International organizations such as the WHO, the World Bank, and national and international non-governmental organizations should ideally encourage and assist countries in collecting global surgery data. Greater investments are needed to improve data collection at the national level.

A set of standardized guidelines for the collection of surgical indicators is crucial to allow both governments and international organizations to improve data collection methods, data reporting, disaggregation, and overall data quality. Such guidelines would offer benefits to both national and international actors in charge of collection and distribution of surgical data in terms of accuracy and compatibility of data. Consensus on such indicators by a group of experts from national statistical authorities, line ministries, international organizations, and academia who are working in this area under the leadership of the WHO Emergency and Essential Surgical Care program would be the most effective way to drive progress forward. The guidelines need to make evident how the collected data will benefit all levels of decision makers, clinicians, hospital boards, politicians at the regional or national level, global organizations, and non-state actors. The message that the benefits outweigh the risks for damage to national prestige must be emphasized.

As progress is made in strengthening health information systems and surgical care delivery, indicators could be further refined to focus on other critical areas including outcomes monitoring, additional aspects of safety, unmet needs, and human impact that are not included in the current indicator set (Table 1) because of concerns about the current feasibility of collecting the supporting data.

There is currently no forum or event that allows discussion centred on global surgery and anesthesia statistics and analysis. An international conference or seminar, focusing on evaluation of the state of global surgery data collection with respect to these statistics, is vital in this regard. Such a conference could bring together experts and interested parties from national statistical offices, Ministries of Health, international and nongovernmental organizations, academia, and industry.

\section{Conclusion}

More data collection and analyses are needed in domains such as identifying the unmet need for and inequalities in access to surgical and anesthetic care at the global, national, and sub-national levels. Data collection also needs to address barriers to seeking care at the individual level, the related types of surgical disease, quality of surgical care, and sub-national distribution in access to these services. Equally important is to register the unmet need and barriers to the data collection itself. The international community has come a long way in the past ten years in both suggesting indicators and attempting data measurement, consolidation, and improvement in health statistics. Now is the time to strive for an international consensus and inclusion of surgical and anesthesia data collection at all levels of international health information systems. Building on lessons learned and experiences of individual countries, as well as responding to new global development frameworks, strategies need to be designed to strengthen national capacity to generate, analyze, and utilize high-quality, relevant, and disaggregated global anesthesia-surgery statistics to inform health system strengthening and sustainable development for the public good. Health statistics are typically implemented as a sectoral project, not as integral part of the statistical ecosystem, which may lead to underfunding. Sustainable financing mechanisms need to be put in place to support LMICs in setting up robust systems. Limited capacity further contributes to poor data collection, delays in release 
of data, and limited in-depth analysis or exploitation of such data. Long-term capacity-strengthening activities need to integrate components to strengthen institutional capacity as well as institutional partnerships and coordination at the regional, national, and sub-national level. Incentives need to be provided to improve knowledge management and sharing.

Conflict of interest The authors declare no conflicts of interest.

Editorial responsibility This submission was handled by Dr. Hilary P. Grocott, Editor-in-Chief, Canadian Journal of Anesthesia.

\begin{abstract}
Author contributions Sabrina Juran originally conceived of the article and its structure and co-wrote the initial drafts. Magdalena Gruendl helped with significant contributions to the manuscript, including concepts, structure, and wording, and also co-wrote initial drafts and formatted references. Isobel $H$. Marks helped with significant contributions to the manuscript, including concepts, structure, and wording, and also co-wrote initial drafts. P. Niclas Broer, Jose Miguel Guzman, Justine Davies, Mark Shrimer, Walter Johnson, Hampus Holmer, Gregory Peck, Emmanuel Makasa, Lars Hagander, Stephanie J. Klug, John G. Meara, and Adrian W. Gelb helped with significant contributions to the manuscript, including concepts, structure, and wording. These authors also reviewed the draft. David Ljungman originally conceived of the article and its structure and co-wrote the initial drafts.
\end{abstract}

Funding sources David Ljungman is funded by the Fulbright Commission, Swedish Medical Society, Björnsson Foundation, Sweden-America Foundation, and Adlerberth Research Foundation. John G. Meara is supported by an unrestricted grant from General Electric Foundation.

\section{References}

1. Price R, Makasa E, Hollands M. Resolution 68.15. Strengthening emergency and essential surgical care and anesthesia as a component of universal health coverage - addressing the public health gaps arising from lack of safe, affordable and accessible surgical and anesthetic services. World Health. Organization 2015; 39: 2115-25.

2. Meara JG, Leather AJ, Hagander L, et al. Global Surgery 2030: evidence and solutions for achieving health, welfare, and economic development. Lancet 2015; 386: 569-624.

3. Shrime $M G$, Bickler SW, Alkire BC, Mock C. Global burden of surgical disease: an estimation from the provider perspective. Lancet Glob Health 2015; 3(Suppl 2): S8-9.

4. Alkire BC, Raykar NP, Shrime $M G$, et al. Global access to surgical care: a modelling study. Lancet Glob Health 2015; 3 : e316-23.

5. Huber $B$. Finding surgery's place on the global health agenda. Lancet 2015; 385: 1821-2.

6. Weiser TG, Haynes AB, Molina G, et al. Size and distribution of the global volume of surgery in 2012. Bull World Health Organ 2016; 94: 201-9F

7. Mock CN, Donkor P, Gawande A, et al. Essential Surgery: Key Messages from Disease Control Priorities, 3rd Edition. Lancet 2015; 385: 2209-19.
8. Shrime $M G$, Dare AJ, Alkire BC, et al. Catastrophic expenditure to pay for surgery worldwide: a modelling study. Lancet Glob Health 2015; 3(Suppl 2): S38-44.

9. Verguet $S$, Alkire BC, Bickler SW, et al. Timing and cost of scaling up surgical services in low-income and middle-income countries from 2012 to 2030: a modelling study. Lancet Glob Health 2015; 3(Suppl 2): S28-37.

10. Alkire BC, Shrime MG, Dare AJ, Vincent JR, Meara JG. Global economic consequences of selected surgical diseases: a modelling study. Lancet Glob Health 2015; 3(Suppl 2): S21-7.

11. United Nations. World Population Prospects. Key findings \& advance tables. 2015 revision. Available from URL: https://esa. un.org/unpd/wpp/publications/files/key_findings_wpp_2015.pdf (accessed August 2018).

12. Kim JY. Opening address to the inaugural "The Lancet Commission on Global Surgery" meeting. The World Bank. Working for a world free of poverty. January 17, 2014 Boston. Available from URL: http://www.globalsurgery.info/wp-content/ uploads/2014/01/Jim-Kim-Global-Surgery-Transcribed.pdf (accessed August 2018).

13. World Health Organization. 2017 Seventieth World Health Assembly. Seventieth World Health Assembly Agenda item 16.1 Progress in the implementation of the 2030 agenda for sustainable developement document A70/35. Available from URL: http://www.who.int/life-course/news/events/70-wha/en/ (accessed August 2018).

14. Hosseinpoor AR, Bergen N, Magar V. Monitoring inequality: an emerging priority for health post-2015. Bull World Health Organ 2015; 93: 591-591A

15. World Health Organization. Global Reference List of 100 Core Health Indicators (plus health-related SDGs), 2018. Available from URL: http://www.who.int/healthinfo/indicators/2018/en/ (accessed August 2018).

16. The World Bank. DataBank. World Development Indicators. Available from URL: http://databank.worldbank.org/data/reports. aspx? source $=$ world-development-indicators (accessed August 2018).

17. The World Bank. Atlas of Sustainable Development Goals. 2018 World Development Indicators. Available from URL: http:// datatopics.worldbank.org/sdgatlas/ (accessed August 2018).

18. World Health Organization. Fact file on health inequities. 2011. Available from URL: http://www.who.int/sdhconference/ background/news/facts/en/ (accessed August 2018).

19. Raykar NP, Ng-Kamstra JS, Bickler S, et al. New global surgical and anaesthesia indicators in the World Development Indicators dataset. BMJ Glob Health 2017; 2: e000265.

20. Kamali P, Marks I, Sama G, Vervoot D. Measuring surgical systems worldwide: an update. The Data Blog - The World Bank - 2018. Available from URL: https://blogs.worldbank.org/ opendata/measuring-surgical-systems-worldwide-update (accessed August 2018).

21. Marks IH, Kamali P, Khan MA, et al. Data for the sustainable development of surgical systems: a global collaboration. WDI surgical indicators data collection 2016. Available from URL: https://docs.wixstatic.com/ugd/d9a674_967bde5252664b709f19e 691bf6732fd.pdf (accessed September 2018)

22. The Lancet Commission on Global Surgery. Global Indicator Initiative. Available from URL: http://www.lancetglobalsurgery. org/indicators (accessed August 2018).

23. World Federation of Societies of Anaesthesiologists. World Anaesthesiology Workforce. Available from URL: https://www. wfsahq.org/workforce-map (accessed August 2018).

24. Program in Global Surgery and Social Change - Harvard Medical School. National Surgical, Obstetric and Anesthesia Planning. Available from URL: https://www.pgssc.org/nationalsurgical-planning (accessed August 2018). 
25. Surgeons Overseas SOS. Surgical Need in the Developing World. Available from URL: https://www.surgeonsoverseas.org/ resources/ (accessed August 2018).

26. The Lancet Commission on Global Surgery. Implementation Tools. Available from URL: http://www.lancetglobalsurgery.org/ implementation-tools (accessed August 2018).

27. Marks IH, Fong ZV, Stapleton SM, Hung YC, Bababekov YJ, Chang $D C$. How much data are good enough? Using simulation to determine the reliability of estimating pomr for resourceconstrained settings. World J Surg 2018; 42: 2344-7.

28. World Health Organization. Framework and Standards for Country Health Information Systems, Second Edition - 2008. Available frm URL: http://www.who.int/healthinfo/country_ monitoring_evaluation/who-hmn-framework-standards-chi.pdf (accessed August 2018).

29. Jha AK, DesRoches CM, Campbell EG, et al. Use of electronic health records in U.S. hospitals. N Engl J Med 2009; 360: 1628-38.

30. Marques ET Jr, Maciel Filho R, August PN. Overcoming health inequity: potential benefits of a patient-centered open-source public health infostructure. Cad Saude Publica 2008; 24: 547-57.

31. United Nations. Department for Economic and Social Affairs. Statistics Division. Principles and Recommendations for a Vital Statistics System, Revision 3, 2014. Available from URL: https:// unstats.un.org/unsd/demographic/standmeth/principles/m19rev3 en.pdf.
32. The DHS Program - Demographic and Health Surverys. The DHS Program - Quality information to plan, monitor and improve population, health, and nutrition programs. Available from URL: https://dhsprogram.com/ (accessed August 2018).

33. United Nations Children's Fund (UNICEF). Statistics and Monitoring. Multiple Indicator Cluster Survey (MICS). Available from URL: https://www.unicef.org/statistics/index 24302.html (accessed August 2018).

34. Program in Global Surgery and Social Change - Harvard Medical School. Surgical Assessment Tool (SAT). Available from URL: https://www.pgssc.org/national-surgical-planning.

35. Blair KJ, Paladino L, Shaw PL, et al. Surgical and trauma care in low- and middle-income countries: a review of capacity assessments. J Surg Res 2017; 210: 139-51.

36. The DHS Program - Demographic and Health Surveys. Service Provision Assessment (SPA). Available from URL: https:// dhsprogram.com/What-We-Do/Survey-Types/SPA.cfm (accessed August 2018)

37. World Health Organization. Service availability and readiness assessment (SARA) 2015. Available from URL: http://www.who. int/healthinfo/systems/sara_introduction/en/ (accessed August 2018). 